\section{EL ARTE RUPESTRE GALAICO: UNA REFLEXIÓN CRÍTICA SOBRE EL PRESENTE Y UNA PROPUESTA PARA EL FUTURO}

\author{
THE GALICIAN ROCK ART: A CRITICAL \\ REFLECTION ABOUT THE PRESENT \\ AND A PROPOSAL FOR THE FUTURE
}

\author{
FERNANDO CARRERA RAMÍREZ (*) \\ FERNANDO J. COSTAS GOBERNA (**) \\ ANTONIO DE LA PENA SANTOS (***) \\ JOSE MANUEL REY GARCIA (****)
}

\section{RESUMEN}

En el artículo se pasa revista a los principales problemas de conservación que afectan a los grabados rupestres galaicos y se propone un Plan de Gestión de los mismos. La idea básica es que se determina un Patrimonio, se evalúa y se actúa sobre el mismo para obtener una protección más efectiva y una mayor rentabilización social. Se sugieren acciones profundas sobre conjuntos relevantes y significativos científica y socialmente.

\begin{abstract}
In the paper it is proposed a management standard for the Galician Rock Art having as basic idea the determination and evaluation of Heritage and, then, to work on it in order to a more effective protection and better social profitabily. General protective measures are considered and deep actions on the scientifically and socially most outstanding units are suggested.
\end{abstract}

(*) Escuela Superior de Conservación y Restauración de Bienes Culturales de Galicia. Cuartel de San Fernando. 36002 Pontevedra.

(**) Museo Municipal de Vigo. Parque de Castrelos, s/n. 36213 Vigo.

(***) Museo Provincial de Pontevedra. Plaza de la Leña. 36002 Pontevedra.

(****) Delegación Provincial de la Consellería de Cultura. Durán Loriga, 9. 15003 Coruña.

El artículo fue remitido en su versión final el 11-IV-94.
Palabras clave: Arte Rupestre Galaico. Gestión. Protección. Legislación.

Key words: Galician Rock Art. Management. Protection. Legislation.

\section{INTRODUCCIÓN}

El millar largo de complejos de grabados rupestres al aire libre sobre soporte granítico que integran lo que en otro lugar hemos definido como "Grupo Galaico de Arte Rupestre" (Peña Santos, 1992; Peña Santos y Rey García, 1993), con su acusadísima personalidad y fuerte carga estética, constituye sin lugar a dudas el fenómeno más peculiar de los producidos en el área galaica durante la Antigüedad (1).

Con una dispersión geográfica coincidente en esencia con el área de las Rías Bajas y pequeñas y puntuales filtraciones hacia el interior y hacia el sur, el repertorio iconográfico de los grabados rupestres galaicos ha sido tradicional-

(1) Alguna bibliografía tradicional sobre el tema puede ser la siguiente: Sobrino Buhígas (1935); Sobrino LorenzoRuza (1955); Anati (1968); Peña Santos y Vázquez Varela (1979); García Alén y Peña Santos (1980); Peña Santos (1984); Vázquez Varela (1990). 
mente dividido en dos grandes bloques temáticos: geométrico y seminaturalista (Fig. 1).

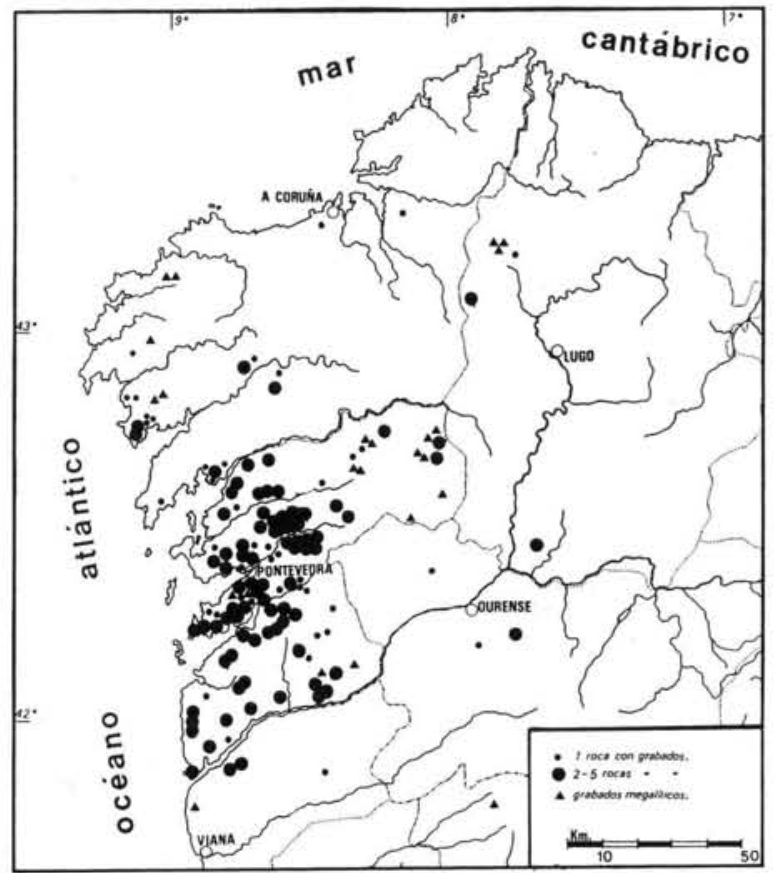

Fig. 1. Área de dispersión geográfica de los complejos de grabados rupestres galaicos.

El bloque geométrico es el más numeroso. Lo integran simples puntos o cazoletas y una amplísima y compleja serie de combinaciones de círculos concéntricos, espirales y trazos diversos. Por su parte, el bloque seminaturalista está compuesto por figuras muy sucintas de ciervos, caballos, serpientes, armas muy concretas -puñales, espadas cortas, alabardas y escudos-, antropomorfos y figuras humanas participando en escenas de cacerías y de equitación.

Recientes estudios están aportando interesantes novedades en el análisis de este fenómeno, concretando su cronología -transición III-II Milenios (Peña Santos, e.p.; Peña Santos y Rey García, 1993) y poniendo de relieve su fortísimo componente simbólico e ideológico (Vázquez Varela, 1991; Peña Santos, e.p.; Peña Santos y Rey García, 1993).

Pese a su evidente relevancia cultural, en los últimos años asistimos a un deterioro tan extraordinario y progresivo que hace temer seriamente por la integridad de este grupo de arte rupestre. Se constata la destrucción total de estaciones completas y la desaparición de numerosos conjuntos particulares; por si ésto fuera poco, la acción de los incendios forestales y del vandalismo están provocando efectos demoledores.

La consciencia de esta situación es la que nos ha movido a presentar este artículo, con el que pretendemos resumir la realidad actual de la conservación del Grupo Galaico de Arte Rupestre y las medidas que se nos ocurren para frenar en la medida de lo posible su deterioro y lograr su necesaria rentabilización social.

\section{AGENTES DE DEGRADACIÓN DEL ARTE RUPESTRE GALAICO}

A lo largo de los siglos se ha venido produciendo una lenta alteración natural que afecta a todos los petroglifos por igual pero que ha permitido su conservación. En efecto, aunque la alteración es considerable, en la mayoría de los casos ni destruye los grabados ni impide su lectura. Frente a ello, en los últimos años, y siempre inducidas por actividades humanas, aumentan cuantitativa y cualitativamente las agresiones, acelerándose el proceso destructivo hasta un punto sin retorno. El momento de poner freno a esta situación parece haber llegado.

\subsection{Agentes naturales}

El régimen climático gallego impide que la meteorización física tenga una relevancia especial sobre nuestros grabados. Los fuertes procesos de lavado derivados de un clima lluvioso impiden el desarrollo de fenómenos de cristalización de sales, al tiempo que la inexistencia de saltos térmicos importantes, ya sean estacionales, ya sean diarios, hace que la alteración térmica sea insignificante.

Aunque en la mayoría de las ocasiones tiene un origen antrópico, podemos introducir en este grupo el efecto de los incendios forestales (Láms. I y II). Con seguridad se trata del más alto factor de alteración en la actualidad, habiéndose constatado importantes pérdidas de grabados en los últimos años (Alvarez Núñez, 1982). Las altas temperaturas alcanzadas durante la combustión del bosque, el diferente grado de expansión térmica de los minerales del granito, $\mathrm{y}$ las diferencias de temperatura entre interior/exterior o zonas cubiertas/descubiertas, son los agentes que traen consigo la aparición de escamaciones (termoclastos) sobre la superficie.

T. P., 51, n. $^{\circ} 2,1994$ 


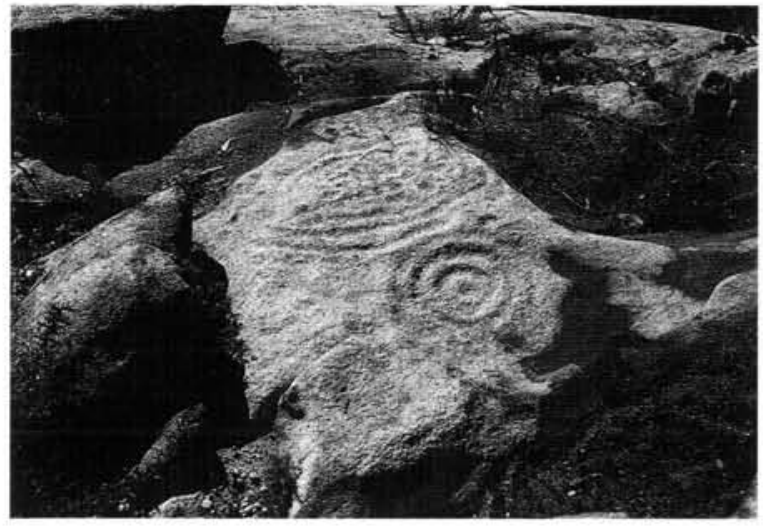

Lám. I. Efectos de los incendios forestales. Pérdida inicial de la pátina protectora; posteriormente surgirán las escamaciones (termoclastas).

Estas escamas, que surgen en un tiempo variable que va desde días a meses, acaban saltando, con la consiguiente pérdida de superficie grabada. Un último elemento de meteorización física a tener en cuenta por su incidencia directa sobre los grabados lo constituye el crecimiento de la vegetación superior -pino, eucalipto y tojo en el caso gallego- hasta el borde mismo de los paneles.

Por contra, el clima gallego sí que favorece el desarrollo de una importante meteorización química. Sin entrar en explicaciones profundas -para las que tampoco estamos capacitados-, podríamos citar la hidrólisis de feldespatos y micas como el factor predominante en este tipo de alteraciones. Como es de sobra conocido, su efecto a largo plazo es una lenta pero progresiva arenización que va suavizando las formas y rebajando los surcos hasta su inexorable desaparición en muchos de los casos.

Pese a que, por fortuna, la mayoría del Patrimonio Rupestre galaico se encuentra alejado de las zonas industriales, es necesario empezar a considerar el aumento de los contaminantes en la atmósfera como un posible potenciador y acelerador de los procesos químicos de meteorización.

Prácticamente, todos los agentes biológicos ejercen una doble acción, mecánica y química, sobre los petroglifos. En general, el proceso más evidente es la agresión física; esto es, el paso de animales, raíces de árboles y arbustos, rizoides de líquenes, etc., siendo más difícil establecer las transformaciones químicas causa-

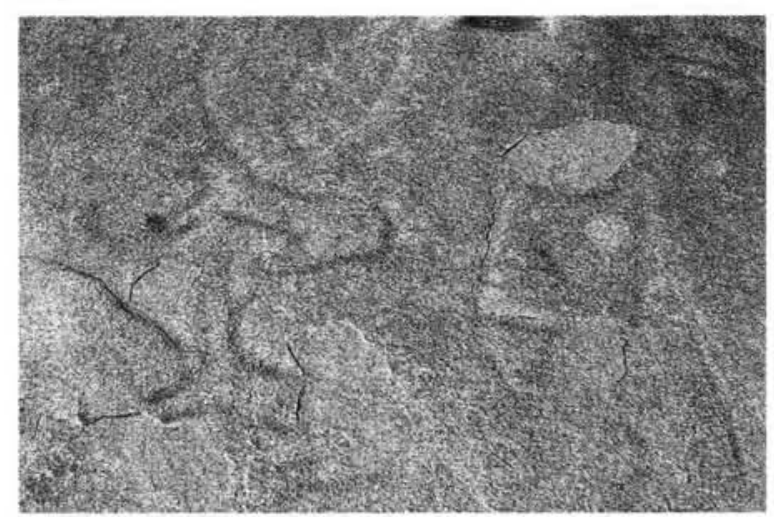

Lám. II. Efectos de los incendios forestales. Escamación de la superficie y pérdida total o parcial de los grabados.

das por ellos, bien conocidas, por el contrario, en el caso de los líquenes. En otros casos -bacterias, por ejemplo-, la investigación no ha progresado lo suficiente, aunque parece que su papel podría ser bastante relevante.

En nuestra opinión, y por lo que a la degradación biológica se refiere, deben considerarse dos procesos negativos. De un lado, el crecimiento de árboles y arbustos en el entorno inmediato de los petroglifos causa importantes agresiones físicas - penetración de raíces a través de las diaclasas- $\mathrm{y}$ favorece el negativo impacto del fuego. De otro, el desarrollo de la importante colonización liquénica tiene un efecto negativo sobre muchas de las rocas grabadas al acentuar la meteorización física y química $(\mathrm{Ca}$ rrera Ramírez, 1987) (Lám. III).

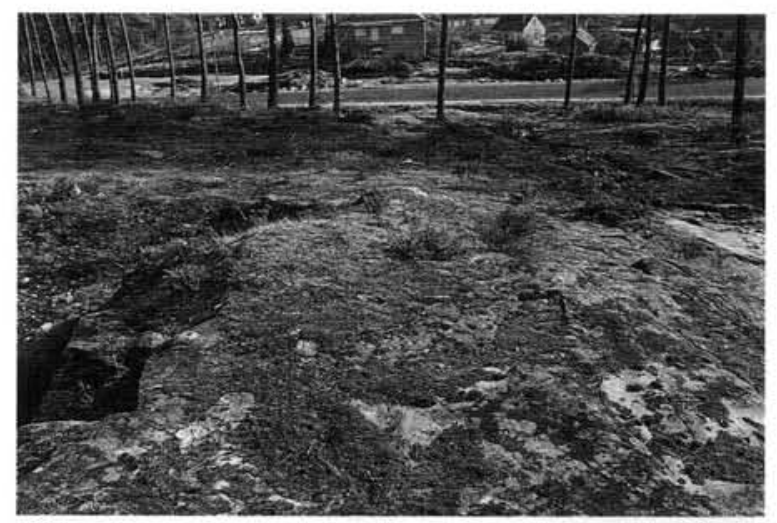

Lám. III. Roca con grabados rupestres muy afectada por colonias de musgos y líquenes, así como por la acción de canteras. 


\subsection{Agentes antrópicos}

Desgraciadamente, los agentes antrópicos son los más graves, hasta el punto de que tal y como ya han señalado algunos autores, el peor enemigo del arte rupestre es el ser humano (Beltrán, 1990: 25). Puede establecerse una distinción inicial entre los que tienen una incidencia física directa sobre la conservación de los grabados y aquellos otros, de incidencia indirecta, que coadyuvan y generan el clima necesario para que las agresiones físicas puedan llevarse, impunemente, a cabo.

\subsubsection{De incidencia directa}

$\mathrm{El}$ agente antrópico directo que tradicionalmente más ha afectado a nuestros complejos rupestres ha sido la labor de extracción de piedra para la construcción, ya sea a pequeña escala (Lám. IV), ya en un nivel de gran explotación industrial. Tanto es así, que son francamente escasos los petroglifos que han llegado íntegros a nuestros días.

Pero las canteras no sólo han supuesto la pérdida, total o parcial, de numerosos complejos rupestres, sino que su acción se deja sentir en otros aspectos, destacando entre ellos las profundas alteraciones en el paisaje causadas por la desaparición de masas rocosas y la acumulación de depósitos de restos de cantería que no sólo sepultan otras rocas con grabados sino que favorecen el crecimiento de vegetación arbustiva y arbórea en lugares antes abiertos.

Directamente relacionado con lo anterior, la apertura incontrolada de vías de comunicación -ya sean pequeños caminos, pistas forestales (Lám. V) o grandes carreteras-, de extraor-

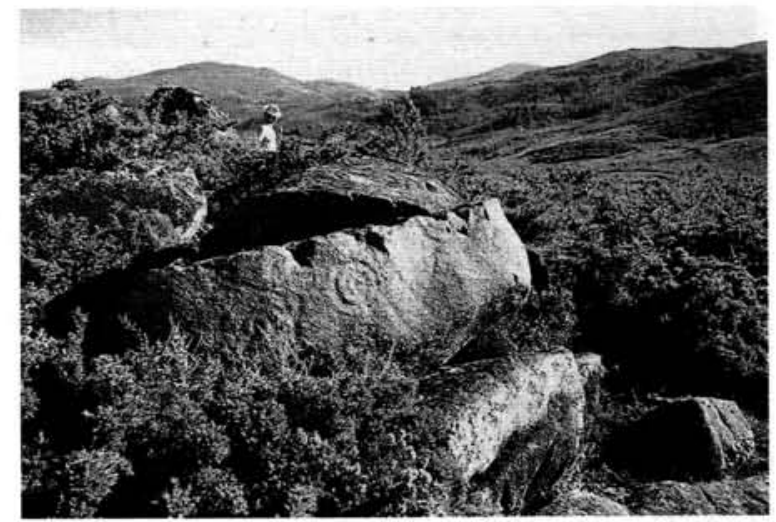

Lám. IV. Efectos de las canteras a pequeña escala, muy comunes en Galicia. dinario desarrollo en Galicia en el último decenio, ha supuesto la destrucción de no pocos grupos de arte rupestre. Muchas de las vías abiertas recientemente están en relación directa con otros agentes directos de destrucción del Patrimonio Arqueológico como son, por poner algún ejemplo, la concentración parcelaria, las roturaciones de terrenos para pastizal, y, por supuesto, la repoblación forestal con especies de rápido crecimiento que además de alterar el paisaje abierto característico de los grabados rupestres, potencian el demoledor efecto de los incendios.

Y ya para finalizar estas breves pinceladas sobre los agentes degradantes de carácter antrópico directo, no dejaremos de mencionar la abrasión de las superficies grabadas causada por los visitantes con la finalidad de resaltar las figuras. A falta de tiza, hemos comprobado hasta la saciedad la existencia de petroglifos remarcados con trozos de ladrillo, piedras de todo tipo (Lám. VI), pinturas acrílicas de todas las gamas y colores, e incluso... con lápiz de labios. No cabe duda que es preciso atajar este grave problema facilitando al observador interesado los medios adecuados para la debida comprensión de los grabados. No se trata de una disquisición teórica, pues está más que demostrado que el público responde de una forma positiva a los yacimientos bien interpretados, con lo que el problema del vandalismo disminuye (Sicari, 1990: 106).

\subsubsection{De incidencia indirecta}

Existen, a nuestro entender, además de los evidentes agentes antrópicos de incidencia física directa, toda una serie de factores que ejercen

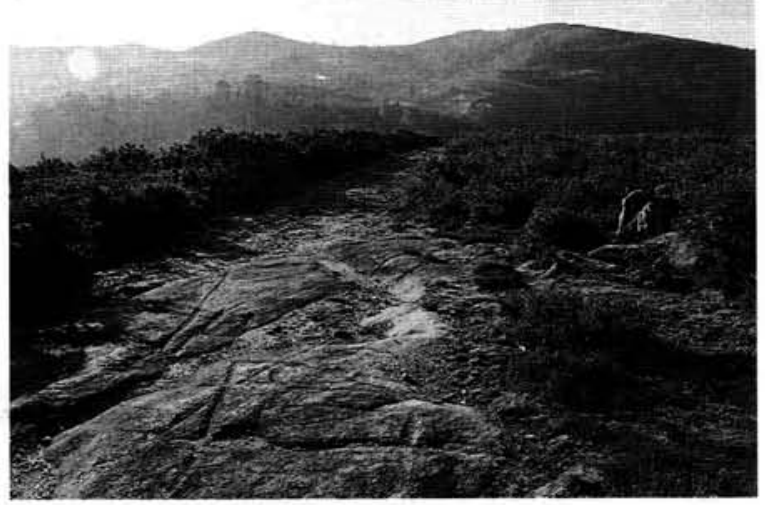

Lám. V. Apertura de una pista forestal sobre una roca con grabados rupestres. 


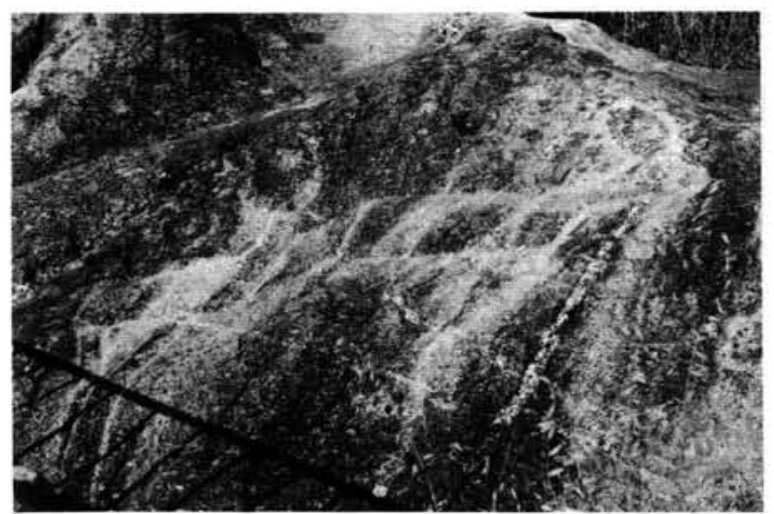

Lám. VI. Otra muestra de frecuente vandalismo: Figuras marcadas con un material de gran dureza, presumiblemente piedra.

una incidencia indirecta en la conservación y la protección de los grabados rupestres en tanto que generan la situación necesaria para que las agresiones físicas se perpetren. $\mathrm{Y}$ en este punto ya no valen excusas. Aquí todos, Administración y arqueólogos, somos culpables. La Administración es culpable, por encima de todo, de no haber puesto todavía los medios necesarios para la elaboración de un Plan General de Protección, coherente, coordinado y eficaz, que dé respuesta a la obligación de conservar el Patrimonio Rupestre que la Ley del Patrimonio Histórico Español le confiere. Es por ello responsable, tanto de no subsanar las más que evidentes lagunas del régimen de protección legal del Patrimonio Arqueológico, como de auspiciar intervenciones sobre los complejos rupestres que van de lo totalmente ineficaz (2) a lo verdaderamente descabellado (3) (Lám. VII). Por nuestra parte, los arqueólogos somos responsables de inhibirnos demasiadas veces ante los peliagudos y conflictivos aspectos que la

(2) Actuaciones como las llevadas a cabo en Campo Lameiro o Cotobade, limitadas a rozar la vegetación circundante, a la habilitación de caminos de acceso y a la instalación de señales, unen a su ineficacia por falta de continuidad en años sucesivos, el deterioro causado por el vandalismo atraido por los carteles indicadores. Parece bastante coherente exigir que se establezcan los mecanismos necesarios para la debida protección de todo aquéllo que se señalice.

(3) Los casos de Mogor (Marín, Pontevedra) -actuación insensata donde las haya- y de Cangas (Pontevedra) -donde se instalaron unos carteles de tamaño tan descomunal que pueden ser vistos facilmente desde la otra orilla de la ría de Vigo- son sólo dos ejemplos significativos. Por supuesto, el deterioro causado por el vandalismo atraido por la señalización es brutal en estos importantes complejos.

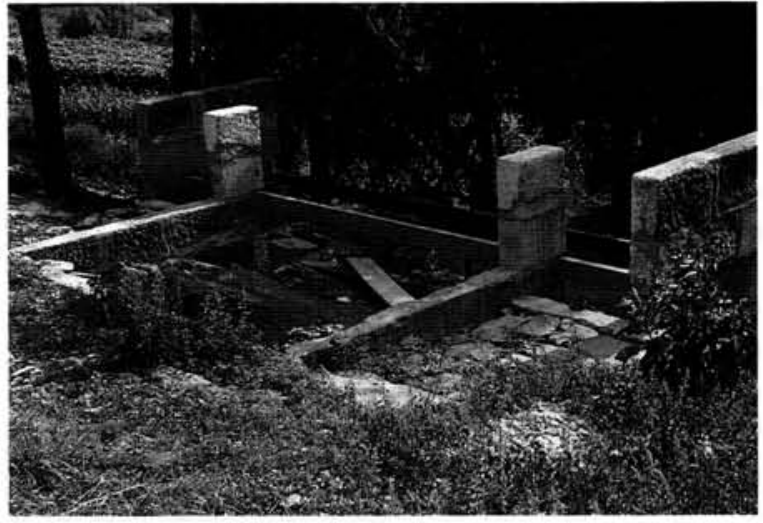

Lám. VII. Ejemplo de actuación oficial en el complejo rupestre de Mogor. Obras para una presunta protección de los grabados.

protección y gestión de nuestro Patrimonio conlleva. También lo somos de perpetuarnos como detentadores de un saber especializado, aislados e indiferentes a la demanda de información del conjunto social. Es justo reconocer, llegados a este punto, que toda generalización genera injusticias, y que de sobra sabemos que hay arqueólogos que a nivel particular se han significado reiteradamente hasta caer en el desencanto ante el nulo efecto que sus denuncias ejercen sobre la Administración, pero no es menos cierto también que casi nunca tenemos presente que uno de los fines que como colectivo profesional nos compete a los arqueólogos es la promoción de la defensa y la divulgación del Patrimonio Arqueológico. Tal vez estemos ante una especie de ingrato círculo vicioso, pero aunque así fuera, ello no nos exime de la parte de culpa que nos corresponde.

\section{EL PLAN DE GESTIÓN DEL PATRI- MONIO RUPESTRE GALAICO}

El Plan que proponemos, lo confesamos, no resulta excesivamente novedoso en cuanto a su concepción general. Presenta ciertas similitudes con las propuestas de otros autores para gestionar el Patrimonio Arqueológico general (Velasco Steigrad, 1992; Barbi Alonso y Carrera Ramírez, e.p.) y el Rupestre en particular (Sicari, 1990). Sin embargo, se aleja de los mismos en cuanto a su desarrollo y estructuración interna. La idea básica es que se determina un Patrimonio, se evalúa y se actúa sobre el mismo con la finalidad de obtener una protec- 
ción más efectiva y una mayor rentabilización social (Fig. 2).

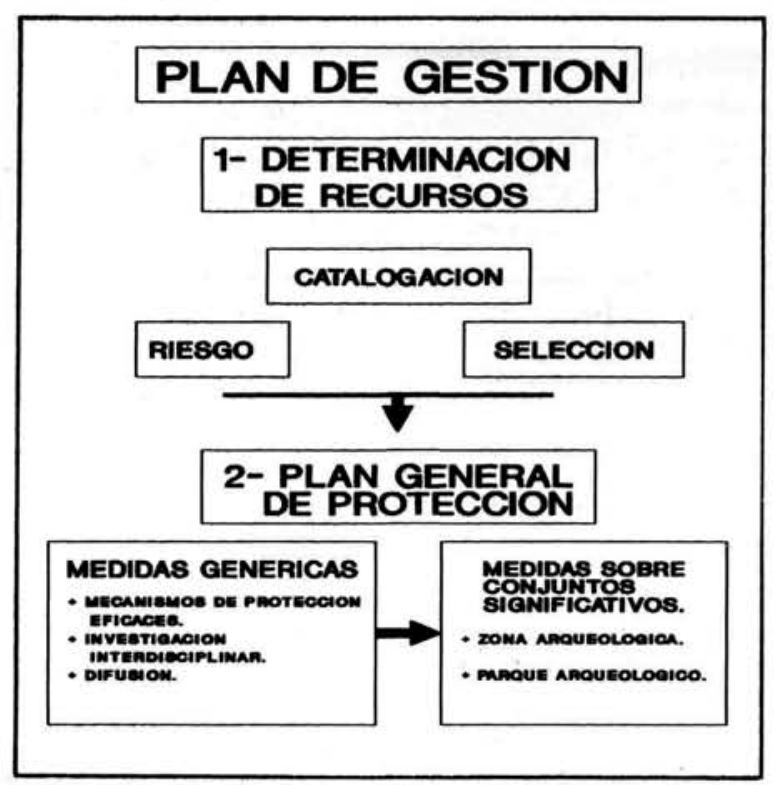

Fig. 2. Esquema general del Plan de Gestión del Patrimonio Rupestre Galaico que se propone en el texto.

\subsection{Determinación de recursos}

Constituye la primera de las fases definidas dentro del modelo de gestión y protección que proponemos (4). En ella, a partir de las técnicas de inventario y catalogación, se produce la determinación de los recursos disponibles para, a continuación y a través de las distintas variables contempladas en la Carta de Riesgo, proceder a establecer las prioridades en cuanto a las actuaciones que se pretende llevar a cabo. Finalmente, el grado de actuación a desarrollar estará condicionado a la relevancia cultural que se defina en el Informe de Valoración.

\subsubsection{Inventario, catálogo y documentación}

Parece lógico suponer que antes de plantearse cualquier tipo de intervención sobre nuestro Patrimonio Rupestre, será preciso contar con un exhaustivo inventario y catálogo de los recursos disponibles. En la actualidad, numerosas y muy diferentes actuaciones llevadas a cabo hasta la fecha nos permiten contar con

(4) Una propuesta similar puede verse en Barbi Alonso y Carrera Ramírez (e.p.).

T. P., 51, n. $^{\circ} 2,1994$ una amplia relación de complejos de grabados rupestres catalogados. Dada la dispersión de estos complejos por una buena parte de nuestra geografía y su más que evidente importancia histórica y relevancia estética, ha existido desde antiguo una cierta preocupación por su inventariado, desde iniciativas totalmente privadas y de carácter personal (Sobrino Buhigas, 1935; Peña Santos, 1978; Alvarez Núñez, 1982; Costas Goberna, 1984, Costas Goberna y Fernández Pintos, 1987), hasta actuaciones más recientes auspiciadas y financiadas íntegramente por la Administración, pasando por catalogaciones subvencionadas en parte por Fundaciones privadas (García Alén y Peña Santos, 1980). Sin embargo, dada la dispersión de estas iniciativas, los trabajos resultantes reflejan una acusada y manifiesta disparidad en cuanto a su concepción y al tratamiento de la información. En este sentido, sería deseable que se llegase a una necesaria estandarización en lo que respecta a la recogida de la documentación, estableciendo unos mínimos al respecto: planimetría, revelado, tipos de calcos, fotografías, reproducciones en látex, silicona o por otros métodos, etc.

Otro de los aspectos que deberían ser abordados dentro de una adecuada estrategia de documentación y registro de nuestros grabados rupestres sería la exigencia de una ficha que recogiese el estado de conservación de cada petroglifo y los factores potenciales de alteración. Tradicionalmente, en el mejor de los casos estos aspectos han sido relegados a un segundo plano, y cuando se contemplan, como es el caso de la actual ficha de catalogación de la Xunta de Galicia, son de todo punto insuficientes y restringidos a aspectos muy concretos y determinados. Debería, pues, elaborarse una ficha estandarizada en la que además de la información usual se plasmasen todos los factores potenciales de alteración. Su posterior tratamiento informático facilitaría enormemente los trabajos y permitiría abordar la elaboración de una Carta de Riesgo.

\subsubsection{La Carta de Riesgo}

Con los datos anteriores en la mano, estaríamos ya en condiciones de elaborar una cartografía en la que se reflejase con detalle la distribución y la concentración de nuestro Patrimonio Rupestre, así como su situación de riesgo potencial frente a los diversos agentes de alteración, tanto de orden natural como antrópicos -inme- 
diatez a canteras o a zonas con elevada presión constructiva, emplazamiento sobre suelo urbano o urbanizable, concentración parcelaria, proximidad a vías de comunicación, etc.-Obtendríamos de esta forma un útil instrumento de trabajo que permitiría el posterior diseño de actuaciones efectivas.

\subsubsection{La selección de los recursos}

Una vez inventariado el Patrimonio Rupestre y determinada su situación de riesgo ante los diversos agentes de alteración, el paso siguiente sería seleccionar los recursos sobre los que diseñar las estrategias de actuación. Parece obvio suponer que el punto de partida debería ser la consideración de que no se puede, ni se debe, intervenir sobre la totalidad de nuestro Patrimonio Rupestre con la misma intensidad, por lo que se hace inevitable el establecimiento de un estricto proceso de selección de aquellos complejos más rentables científica y socialmente.

Ya en trabajos precedentes, alguno de nosotros ha señalado los criterios que deberían regir este proceso de selección. En tal sentido, sería necesario contemplar criterios relevantes para la sociedad en general -económico/utilitario, estético/ artístico o asociativo/simbólico-, evitando la consideración exclusiva de aquellos valores que el arqueólogo suele considerar más importantes; es decir, el científico o el histórico (Carrera Ramírez y Barbi Alonso, 1992: 23). Sólo de esta manera estaríamos en condiciones de garantizar que nuestra valoración fuera coincidente con la que la sociedad en general haría del yacimiento en cuestión.

\subsection{El plan general de protección del Arte Rupestre Galaico}

Tras los trabajos anteriormente señalados, deberíamos estar ya en condiciones de definir, con criterios objetivos y con la suficiente y deseada exactitud, los siguientes extremos:

- La extensión e importancia del Arte Rupestre Galaico.

- Su estado de conservación.

- Los factores de riesgo que condicionan su conservación.

- Las prioridades de actuación para limitar los factores de riesgo más importantes.

- Los grupos objetivamente seleccionados para el desarrollo de actuaciones más profundas a partir de la declaración de Bien de
Interés Cultural con categoría de Zona Arqueológica y su posible conversión en áreas visitables o Parques Arqueológicos.

La adopción de una política eficaz de conservación debe constituir uno de los pilares sobre los que se asiente la actuación administrativa en el diseño de un Plan General de Protección que se aleje de criterios basados en la disparidad y en la improvisación. En este sentido, y para evitar los problemas creados por la desigualdad de las actuaciones realizadas hasta el presente, consideramos que sin duda habría sido bastante más interesante y fructífero haber destinado una mínima parte del dinero invertido en actuaciones puntuales a ponerse de acuerdo en qué es lo que debemos hacer con nuestro Patrimonio Rupestre para conseguir que éste llegue a ser contemplado y apreciado por las generaciones futuras.

El Plan General de Protección trataría pues, en esta segunda fase, de establecer los mecanismos adecuados para la protección del Patrimonio Rupestre evaluado en la anterior fase de Determinación de Recursos, reflexionando sobre los aspectos normativos de la protección, y potenciando su rentabilización social a partir de la conversión de determinados conjuntos significativos en áreas visitables o, en el mejor de los casos, en Parques Arqueológicos.

Este Plan debería partir de la asunción de que no todos los complejos rupestres pueden ser protegidos con la misma intensidad, a pesar de que todos deben contar con unas medidas mínimas de protección. Por ello, se establecen propuestas a dos niveles: inicialmente, medidas de protección general; con posterioridad, acciones profundas sobre los conjuntos más relevantes y significativos desde un punto de vista científico y social.

\subsubsection{Una reflexión en torno a las medidas ge- néricas de protección}

Resulta lógico suponer, en principio, que es a la Xunta de Galicia, en tanto que ente obligado a la tutela y gestión de nuestro Patrimonio Arqueológico, a quien compete la promoción de un marco adecuado para el establecimiento de un Plan General de Protección del Arte Rupestre Galaico que reflexione, críticamente, sobre tres aspectos que, a nuestro entender, tienen una especial incidencia sobre el régimen de protección y conservación de nuestros complejos rupestres: 


\section{a) El establecimiento de mecanismos de protección eficaces}

En virtud del imperativo constitucional (5), la Administración competente debe ser la primera en plantear la necesidad de establecer mecanismos de protección eficaces que partan, inicialmente, de la racionalización y de la reflexión sobre el desarrollo de su propia actividad. En nuestra opinión, esta reflexiva política institucional debería atender a determinados elementos que inciden directamente sobre el Patrimonio Arqueológico en general y el Rupestre en particular.

Un primer punto para la reflexión lo constituye la potenciación de los aspectos jurídicos de la protección del Patrimonio. Parece obvio suponer que el punto de partida debería ser la exigencia de cumplimiento de la normativa legal vigente para, a partir de aquí, potenciar los mecanismos de protección que contempla la Ley del Patrimonio Histórico Español y suprimir las evidentes lagunas jurídicas que condicionan la protección de nuestro arte rupestre (6). En este sentido, consideramos de suma importancia la solicitud de su declaración como PATRIMONIO DE LA HUMANIDAD, tal y como acontece con otros focos de grabados rupestres mundiales, muchos de ellos de bastante menor relevancia que los galaicos. Esta declaración significaría la garantía del incremento de la protección legal y la posibilidad de acceder a fondos comunitarios, lo que permitiría, a su vez, aligerar la carga económica que su protección supondría para la Administración Autonómica.

Un segundo aspecto a considerar es la coordinación institucional. Es bien sabido que en nuestra Carta Magna (7) la coordinación y la

(5) Art. $46 \mathrm{CE}$ : "Los poderes públicos garantizarán la conservación y promoverán el enriquecimiento del Patrimonio Histórico, Cultural y Artístico de los pueblos de España y de los bienes que lo integran, cualquiera que sea su régimen jurídico y su titularidad. La ley penal sancionará los atentados contra este Patrimonio".

(6) En este sentido es realmente ilustrativa la situación existente al respecto de la repoblación forestal, sin lugar a dudas uno de los factores de riesgo más importantes para nuestros grabados rupestres. Al no requerir licencia municipal, escapa con mucha más frecuencia de la deseada al control y fiscalización por la Administración competente para la protección del Patrimonio Arqueológico.

(7) Art. 103.1 CE: "La Administración Pública sirve con objetividad los intereses generales y actua de acuerdo con los principios de efícacia, jerarquía, descentralización, desconcentración y coordinación, con sometimiento pleno a la Ley y al Derecho".

T. P., 51, n. $^{\circ} 2,1994$ eficacia constituyen imperativos legales que no siempre son atendidos en la medida en que sería necesario. Creemos que todos los que de una $\mathrm{u}$ otra forma estamos relacionados con el mundo de la Arqueología somos conscientes de que, desafortunadamente, este es un problema de bastante más relevancia de lo que el sentido común podría dar a entender. La falta de coordinación y, a veces, incluso la beligerancia entre distintas Consellerías, ha traido consigo una importante destrucción de Patrimonio Arqueológico en general y complejos rupestres en particular. Pensemos simplemente, al menos en el caso gallego, en las obras de infraestructura viaria, en la concentración parcelaria, en la apertura de áreas de pastizal, o en la repoblación forestal. Tres cuartos de lo mismo ocurre con obras promovidas por Ayuntamientos y Diputaciones Provinciales que escapan, con frecuencia, al debido control de la Administración competente para la tutela y gestión del Patrimonio Arqueológico. En este sentido, parece lógico pensar que sería necesario establecer los adecuados mecanismos de coordinación necesarios para una efectiva y eficaz protección del Patrimonio Arqueológico.

Un último elemento a contemplar dentro del establecimiento de mecanismos de protección eficaces lo constituye la fiscalización de la normativa sectorial de aplicación en el régimen de protección del Patrimonio Arqueológico. El importante volumen de obras de todo tipo, derivadas del "presente desarrollismo" lleva parejo el incremento del riesgo de que nuestro Patrimonio Rupestre se vea afectado. Parece tarea imprescindible fomentar la presencia, bien a nivel institucional, bien a nivel particular, de los arqueólogos en todas aquellas situaciones en las que exista riesgo de menoscabo de nuestro $\mathrm{Pa}$ trimonio. En este sentido, la beligerancia en los proyectos de planeamiento urbanístico municipal, en los de impacto ambiental y en todas aquellas acciones que supongan la más mínima remoción de tierras sobre zonas de riesgo potencial, debería ser el camino a seguir.

\section{b) La importancia de la investigación inter- disciplinar}

Otro de los aspectos a considerar por parte de la Administración competente debería ser la urgente puesta en marcha de la investigación interdisciplinar necesaria para atajar ciertos procesos de degradación de los grabados y cer- 
tificar la idoneidad de determinados tratamientos de conservación. Es preciso abordar, de forma inmediata y decidida, determinadas lagunas de conocimiento que son imprescindibles para ciertas actuaciones sobre el Arte Rupestre Galaico. Algunos de estos interrogantes serían:

- Acción meteorizadora de los líquenes: conveniencia de su eliminación y sistemas para hacerlo.

- Conveniencia de la consolidación del panel en los casos de fuerte meteorización: productos y sistemas para hacerlo.

- Sistemas para una mejor visión de los petroglifos: pinturas, plataformas de observación, etc.; conveniencia de su utilización.

- Sistemas de tratamiento del entorno de las rocas grabadas: tratamientos edafológicos, eliminación de la vegetación y depósitos recientes (Lám. VIII) y su sustitución o no por césped, vías de acceso a los complejos rupestres, etc.

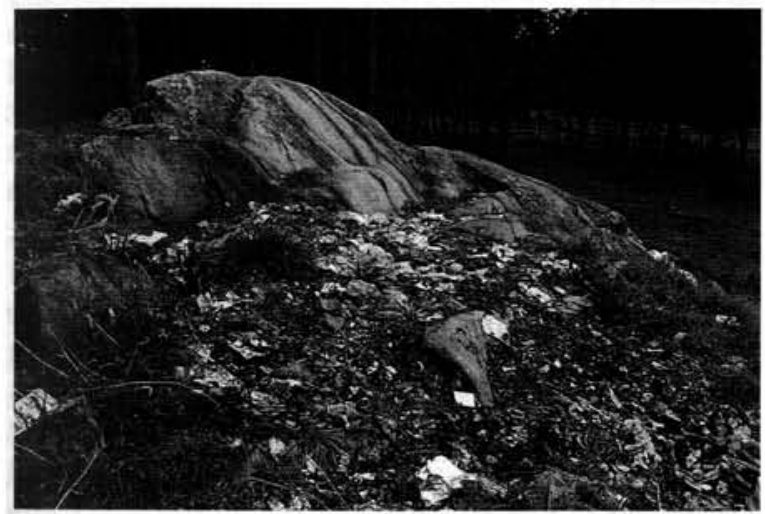

Lám. VIII. Mínimo ejemplo de vandalismo: Basurero sobre una roca con grabados rupestres.

\section{c) EI desarrollo de una adecuada política de difusión}

Resulta obvio suponer que el último aspecto a considerar en la política de protección de nuestros complejos rupestres debería ser el desarrollo de actuaciones de tipo cultural y educativo que favorecieran su aprecio y defensa por el gran público. La Administración y los arqueólogos debemos acostumbrarnos a pensar que, afortunadamente, el arte rupestre es algo que también interesa a la sociedad. Es tarea de la Administración competente en general, y de los arqueólogos en particular, la preocupación porque las actuaciones financiadas con cargo al era- rio público reviertan, en virtud del derecho constitucional a la cultura, en la masa social. La creación de áreas visitables constituye, en tal sentido, no la única pero sí una de las medidas que se nos antojan más eficaces.

\subsubsection{Reforzamiento de la protección legal y rentabilización social: una propuesta para la gestión de conjuntos significativos}

\section{a) La declaración de Zona Arqueológica}

Uno de los avances más importantes que se ha producido en Arqueología en las últimas décadas ha sido la incorporación del contexto espacial en el que se enmarcan los yacimientos arqueológicos para su adecuada valoración e interpretación. En el caso que nos ocupa, los grabados rupestres se asocian a un paisaje característico, de relieves suaves y amplio dominio visual, definiendo lo que algunos de nosotros hemos caracterizado como "el espacio de la representación" (Peña Santos y Rey García, 1991). Parece lógico suponer, pues, que una correcta política de protección y recuperación de nuestro arte rupestre considere, además de los propios paneles grabados, el contexto espacial y paisajístico en el que se engloban. Esta especial sensibilidad por el contexto ambiental ya fue puesta de manifiesto por el legislador en la Ley del Patrimonio Histórico Español al contemplar -eso sí, de forma bastante ambigua y genérica-, el entorno en su articulado (8).

Esta espacialidad, a partir de la cual las manifestaciones arqueológicas adquieren sentido, es recogida de nuevo en la definición de Zona Arqueológica (9). Su declaración como Bien de Interés Cultural, a pesar de constituir el mecanismo más eficaz que la Ley 16/1985 contempla para la protección de los grabados rupestres, presenta, como veremos, graves limitaciones en su aplicación práctica. Las más importantes y reiteradamente repetidas consecuencias jurídicas derivadas de dicha declaración son:

- La suspensión, desde el momento de la incoación de expediente de declaración de interés cultural respecto de un bien inmueble, de las licencias municipales de parcelación,

(8) Véase para esta problemática García Bellido (1988).

(9) "Zona Arqueológica es el lugar o paraje natural donde existen bienes muebles o inmuebles susceptibles de ser estudiados con metodología arqueológica, hayan sido o no extraidos y tanto si se encuentran en la superficie, en el subsuelo o bajo las aguas territoriales españolas" (Art. 15.5 LPHE). 
edificación o demolición de las zonas afectadas, así como de los efectos de las ya otorgadas (Art. 16.1 LPH).

- Se obliga así al municipio o municipios en los que se encontrare a redactar un Plan Especial de Protección del área afectada por la declaración, u otro instrumento de planeamiento de los previstos en la legislación urbanística (Art. 20.1 LPH), lo que supone involucrar, de forma más efectiva, a los municipios en la protección de su Patrimonio Arqueológico superando, de esta forma, el limitado y restrictivo marco del artículo 7 de la Ley.

- Se fiscaliza toda remoción de obras en la zona, pudiendo la Administración competente, bien paralizar la obra (Art. 37.1 LPH), bien ordenar la realización de prospecciones, y en su caso excavaciones, arqueológicas (Art. 22.1 y $43 \mathrm{LPH}$ ), pudiéndose llegar, dado el caso, a la expropiación forzosa (Art. $36.4 \mathrm{LPH})$.

Sin embargo, ya hemos aludido anteriormente a la existencia de graves problemas de aplicación práctica en el régimen de las Zonas Arqueológicas. En este sentido, el primero es el de su propia delimitación. La delimitación a partir de coordenadas geográficas traspasadas a un frío papel no parece el más adecuado de los sistemas. Más bien, aunando criterios arqueológicos y urbanísticos, debería procederse a una delimitación gráfica sobre el plano que pudiera ser fácilmente identificada, utilizando para ello como sistema de referencia los accidentes geográficos del terreno, las infraestructuras existentes, las parcelaciones o incluso los usos actuales del suelo; es decir, aquellos elementos de referencia de fácil percepción visual y siempre teniendo muy en cuenta las particularísimas características naturales y culturales del país gallego.

Por otra parte, la prohibición de construir sobre una Zona Arqueológica que la Ley 16/1985 regula, parece más ficticia que real. Si bien es cierto que el antedicho artículo 37.1 faculta a la Administración competente a paralizar cualquier obra que afecte a un bien arqueológico, también lo es que en ninguna parte del articulado se prohibe, expresamente, la construcción dentro de una Zona Arqueológica, siempre que la misma se ajuste a la calificación del suelo (10). Abundando en este sentido, y en

(10) No obstante, las Normas Complementarias y Subsidiarias de Planeamiento de las provincias de La Coruña, el caso gallego, tampoco está claro que dicha calificación pueda ser determinada por la Administración competente en materia de $\mathrm{Pa}$ trimonio Histórico, y sí lo es, en cambio, por la de Urbanismo. ¿Qué pasaría si la declaración de Bien de Interés Cultural con categoría de Zona Arqueológica, con todas las teóricas bendiciones y protecciones que la Ley del Patrimonio le confiere, se solapara espacialmente con suelo calificado por el planeamiento urbanístico como urbano o urbanizable? (11). Prosigamos. El artículo 22.2 de la Ley prohibe la instalación de cables y publicidad aparente, pero $¿$ se obliga en algún sitio de la misma a retirar esas instalaciones cuando su existencia es previa a la declaración de Zona Arqueológica?.

Las lagunas de la Ley del Patrimonio Histórico se nos antojan más que evidentes. Creemos que existe una manifiesta y peligrosa desvinculación entre la legislación urbanística y la del Patrimonio Histórico. Si de verdad deseamos avanzar en una correcta política de protección y de conservación de los yacimientos arqueológicos, si queremos que el espíritu de la Ley del Patrimonio y la práctica y la realidad diarias sean una misma cosa, parece tarea inaplazable proceder a una armonización y convergencia entre estas dos legislaciones.

\section{b) La conversión en áreas visitables o Par-} ques Arqueológicos: el Plan de Actuación

Establecida la protección legal, el siguiente paso debería ser la redacción de un Plan de Actuación orientado a su difusión y rentabilización social. El punto de partida de esta última etapa

Lugo, Orense y Pontevedra, de 14 de mayo de 1991 (Diario Oficial de Galicia n ${ }^{\circ} 116$ de 19 de junio), establecen para los grabados rupestres un radio de protección de $200 \mathrm{~m}$., dentro del cual será preciso el informe previo y vinculante de la Comisión Territorial de Patrimonio para la realización de cualquier tipo de obra. Aquí sí que se prohibe construir, pero curiosamente, se trata de una normativa urbanística, no de $\mathrm{Pa}$ trimonio Histórico... Otra cosa es que se incumpla de forma reiterada.

(11) En este sentido, según la Sentencia de 3 de octubre de 1986 del Tribunal Supremo, "Las Normas Urbanísticas y las que regulan el Patrimonio Histórico responden a hipótesis diferentes, prevaleciendo las segundas en caso de conflicto en función del derecho a la Cultura, a cuya defensa responde, y en consecuencia, los órganos encargados de la conservación y defensa de este Patrimonio no están vinculados por las Normas Urbanísticas o de cualquier otra materia, y pueden separarse de ellas y adoptar e imponer las limitaciones que discrecionalmente estimen necesarias para dicha defensa". Tal vez sea un planteamiento excesivamente optimista para que tenga una plasmación real efectiva. 
en el modelo de gestión del arte rupestre galaico que proponemos, lo constituye nuestra firme creencia en que la divulgación y la difusión de nuestro Patrimonio Arqueológico genera un mayor aprecio por el mismo y, en última instancia, constituye un mecanismo que potencia y reafirma la protección legal. Además, parte de la asunción de la onerosa deuda que para con la sociedad tenemos los arqueólogos. Consideramos que debe ser tarea común avanzar en el camino de establecer mecanismos de compensación de tipo cultural y social que garanticen el disfrute por parte de la masa social de aquellas actividades que financia. Disponemos, en nuestra opinión, de dos caminos para ello: de un lado, socializar el discurso arqueológico potenciando su componente divulgativo sin que ello suponga renunciar, obviamente, al científico; de otro, convirtiendo estas zonas, una vez dotadas de los oportunos sistemas de protección, en áreas visitables y, si ello es posible, en Parques Arqueológicos, el más útil e importante mecanismo para rentabilizar socialmente nuestro Patrimonio Rupestre.

El Plan de Actuación para la creación de un Parque Arqueológico (12) debería ir precedido de una Fase de Estudio (Carrera Ramírez, 1993) en la que se considerasen aspectos tan variados como los factores de alteración específicos, cuestiones legales diversas -propietarios, servidumbres de paso, etc.-, infraestructuras, etc. Esta fase de estudio no constituye una elucubración teórica, sino que tiene tal importancia que podría ser posible que una vez realizada se llegase a desestimar, dada la magnitud de los problemas que se plantean, seguir adelante con el Plan de Actuación. Tras esta fase estaremos en condiciones de establecer los objetivos generales y las líneas de actuación, con lo que podríamos pasar a la Fase de Proyecto.

En el Plan de Actuación deberían contemplarse actuaciones directas e indirectas.

\section{Actuaciones directas}

Las propuestas que siguen deben considerarse de carácter hipotético, pues no dejan de

(12) Según una definición ampliamente difundida, "Un Parque Arqueológico es un instrumento de intervención y gestión del Patrimonio, entendido como "cultura material"; orientado a su tutela y reserva, a la exposición de sus componentes históricos y a facilitar su comprensión, uso y disfrute público" (García Blanco y Caballero Zoreda, 1992: 375). constituir meras sugerencias ante la relevancia del objeto a tratar y el insuficiente conocimiento de muchos de los tratamientos que se proponen. Surgen de nuestra larga experiencia en el estudio de los grabados rupestres y de la convivencia durante muchos años con esta problemática. En todo caso, y dado que más arriba hemos citado la necesidad de desarrollar ciertas investigaciones sobre esta temática, el propio Parque Arqueológico sería el lugar idóneo para la experimentación de dichos tratamientos.

Las actuaciones directas se ejercen sobre los propios paneles grabados o sobre su entorno más inmediato, y tienen un doble objetivo: de un lado, favorecer la detención de ciertos procesos de alteración; de otro, mejorar la legibilidad de los petroglifos en los casos en que esta sea insuficiente.

Ya hemos establecido con anterioridad el estado de conservación y los factores de alteración que, hoy por hoy, afectan a nuestros grabados rupestres. De todo ello se deduce que es urgente la toma de decisiones, siempre como acciones muy sopesadas y desde posiciones de extremo respeto. En nuestra opinión, es útil pensar que los grabados han llegado a nosotros tras una prolongada y lenta alteración a lo largo de cuatro milenios, por lo que se deben rechazar acciones profundas e irreversibles.

- La eliminación de los depósitos recientes:

Constituye una de las tareas prioritarias la eliminación de derrubios, restos de canteras y de cualquier actividad antrópica reciente. Evidentemente, esta tarea debe estar sometida a un estricto control arqueológico, al ser muy posible la aparición de restos relacionados con el grabado de los petroglifos y, con total seguridad, el descubrimiento de nuevos grabados bajo la ingente masa de depósitos. La supresión de estas acumulaciones, que reduciría al tiempo algunos aspectos de alteración biológica -raícesy física -incendios-, estaría avalada por excavaciones arqueológicas relativamente recientes que confirman la modernidad de los depósitos que cubren y rodean muchas de las superficies grabadas (Peña Santos, 1981:59; 1982; 19841985) (13).

(13) Agradecemos al prof. Vázquez Varela el dato, en el mismo sentido, procedente de la excavación en la Pedra das Ferraduras (Cotobade, Pontevedra). 
- El control de árboles y arbustos:

La acción de la vegetación es de las más perjudiciales, y su eliminación no representa peligro por efecto secundario alguno para la conservación de los petroglifos. Las tareas periódicas de roza, además del coste económico que suponen, se han revelado absolutamente ineficaces. Tampoco es recomendable el empleo de los tradicionales herbicidas químicos por sus posibles efectos negativos sobre el entorno y los todavía no bien definidos sobre la piedra. Por tanto, nuestra propuesta se orienta a la eliminación de la vegetación circundante y su sustitución por hierba baja cuando sea necesario, con un posible tratamiento intermedio del suelo, bien a través de su enriquecimiento, bien mediante el cambio de su PH.

- La limpieza de los paneles grabados:

Puede tener efectos negativos si no se rige por ciertos criterios. Debe entenderse como una tarea de mantenimiento en la que la prudencia ha de ser extrema, evitando para ello el empleo de agentes químicos agresivos -tales como ácidos y bases fuertes- y de sistemas mecánicos fuertemente agresivos. Debe contemplarse también la eliminación de los residuos de los tratamientos empleados. En casos de poca complicación, el uso de cepillo suave empapado en abundante agua con jabón neutro se ha revelado muy positivo para eliminar la suciedad adherida a la superficie sin afectar a la pátina natural protectora. No obstante, se hace preciso experimentar más tratamientos.

- Los líquenes:

El caso de los líquenes es especialmente delicado debido al doble efecto que producen sobre el sustrato: de un lado provocan un lento efecto destructivo; de otro, proporcionan una considerable protección frente a otros agentes de alteración. La penetración de rizoides a través de los cristales de la roca hace que la eliminación de los líquenes conlleve una segura agresión a la misma, ya sea disgregando una parte superficial, ya sea dejándola abierta a la penetración de otros agentes de alteración. Por tanto, y aunque se conocen productos que facilitan la eliminación de las colonias liquénicas (Caneva y Salvadori, 1988), no recomendamos su utilización en tanto no se haya realizado un estudio profundo de sus efectos. Lo que sí parece fuera de toda duda es que, en casos puntuales, la supresión de las capas de líquenes que cubren muchos de nuestros grabados rupestres es inevitable para poder observar, y en su caso destacar, las figuras.

\section{- La consolidación:}

Se hace necesaria la aplicación de tratamientos de consolidación química en ciertos grabados muy deteriorados, pero adoptamos el mismo criterio preventivo anterior; esto es, no actuar en tanto no se conozcan bien los efectos a largo plazo de las sustancias empleadas. Los requerimientos de una efectiva consolidación -penetración profunda, permeabilidad, reversibilidad, hidrorrepelencia, etc.- y la dificultad de aplicación "in situ", nos hacen ser extremadamente cautelosos a la hora de sugerir el empleo de productos químicos sobre los petroglifos en tanto, insistimos, no se hayan experimentado debidamente.

- El pintado de los grabados:

Muchas de las agresiones que sufren los petroglifos son fruto del deseo del espectador por poder observarlos mejor. La propuesta de pintarlos tiene, por tanto, un objetivo eminentemente protector al producir una sensible mejora en la lectura de los mismos por parte del profano. Por el momento, y a falta de que se conozca una pintura de recomendable aplicación por su permeabilidad y reversibilidad, nuestra propuesta se basa en el simple uso de pigmentos sin aglutinar, que si bien presenta como única desventaja aparente la temporalidad de la actuación y la consiguiente necesidad de repetirla cada primavera, ofrece como contrapartida una sencillísima reversibilidad y nula agresividad.

El método que proponemos es una variante mejorada y debidamente contrastada del tradicional "bianchinero" o bicromático (Anati, 1976; Borgna, 1980: 18). Tras la limpieza del panel grabado siguiendo las directrices más arriba expuestas, se aplica con esponja dura y cuidadosamente un pigmento disuelto en agua que reproduzca el color de la roca antes de su limpieza. Con ello se logra la perfecta visión de los surcos de los grabados, ya que éstos contrastarán con el entorno al presentar la pátina natural de la roca, sensiblemente más clara. Este método, además de sus nulos efectos agresivos -no olvidemos además que el pigmento no se aplica nunca sobre el surco sino sobre la superficie no grabada- presenta la gran ventaja de revelar el estado preciso de los surcos, sin la dosis de subjetividad y el falseamiento que pro-

T. P., 51, n. $^{\circ} 2,1994$ 
ducen los sistemas que se basan en marcar el interior de los mismos. Su reversibilidad (14) permite además la eliminación sencillísima del pigmento si la ocasión -algún estudio técnico, por ejemplo- así lo requiriese.

- La reproducción directa de los grabados:

La reproducción directa de los grabados se debe al interés por obtener una documentación lo más fidedigna posible de los mismos. Como ya hemos reiterado, cualquier tipo de tratamiento ha de ser convenientemente valorado: hay determinados sistemas de reproducción -calcos, por ejemplo- que en principio no parecen representar riesgo alguno; otros, como los moldes, pueden producir ligeras alteraciones por la capacidad adhesiva de los materiales de moldeo: látex, silicona, etc.. Por tanto, $\mathrm{y}$ a riesgo de parecer repetitivos, sugerimos el estudio y la experimentación previos a la generalización de los tratamientos. En todo caso, y como documentación imprescindible de aquéllos grabados con riesgo inminente de desaparición, se propone, sin dudarlo, el moldeo de los mismos, recomendándose para ello, dada su fiabilidad y durabilidad, el empleo controlado de la silicona.

\section{Actuaciones indirectas}

Se orientan básicamente a determinados aspectos didácticos y de difusión que exigen la participación de otros profesionales ajenos a la Arqueología -museólogos, paisajistas, arquitectos, ingenieros, antropólogos, etc.-. Es por ello por lo que no podemos ni debemos extendernos en este apartado.

Las acciones indirectas sólo podrán ser decididas en cada caso particular. Sin embargo, no podemos dejar de mencionar, siquiera de pasada, la necesidad de facilitar la observación de determinados complejos por medio de la instalación de discretas plataformas y entarimados de madera a semejanza de los existentes desde antiguo en otras zonas europeas de arte rupestre (15). De igual manera, se hará precisa la apertu-

(14) Para evitar que suceda algo semejante a los efectos claramente negativos que el uso de pinturas acrílicas de difícil reversibilidad está ocasionando en determinadas zonas europeas con arte rupestre. Es el caso, por ejemplo, de los complejos rupestres de Luine-Crape en Italia (Riba, 1984), Alta en Noruega (Helskog, 1986) o Vitlycke en Suecia (Christiansen y Rolstholm, 1986).

(15) Ejemplos relevantes pueden verse en los parques de Naquane en Italia (Riba, 1984), Alta en Noruega (Helskog, 1986) y Vitlycke en Suecia (Christensen y Rostholm, 1986). ra de accesos a los complejos con los debidos aparcamientos, señalizaciones, etc. Tema aparte es el de la información general, que debería partir de la instalación de señales codificadas en las principales vías de comunicación, para traducirse en el lugar en todo un sistema específico pero discreto; al respecto, se hará necesaria la existencia de un edificio en el que, como mínimo, el vistante pueda hacer acopio de la documentación necesaria: mapas de rutas, folletos y bibliografía explicativa, sistemas audiovisuales, etc., etc. Ello serviría además para la necesaria autofinanciación del Parque. En todo caso, insistimos una vez más, este tipo de actuaciones sólo podrá ser diseñado en casos concretos (16).

\section{BIBLIOGRAFÍA}

Álvarez Núnez, A. (1982): Los petroglifos de Campo Lameiro. Tesis de Licenciatura inédita. 3 vols. Ejemplares en el Departamento de Historia-1 de la Universidad de Santiago de Compostela.

ANATI, E. (1968): Arte rupestre nelle regioni occidentali della Penisola Iberica. Archivi di Arte Preistorica, 2. Brescia.

- (1976): Metodi di rilevamento e di analisi dell'arte rupestre. Studi Camuni, 7. Capo di Ponte.

Barbi Alonso, V. y Carrera Ramírez, F. (e.p.): "Protección del Patrimonio Arqueológico inmueble: Un incómodo reparto de tareas y responsabilidades". Actas del XXII Congreso Nacional de Arqueología (Vigo, 1993).

Beltrán Martínez, A. (1990): "Los Parques Culturales y el arte rupestre en Aragón”. Jornadas sobre Parques con Arte Rupestre (Zaragoza, 1989): 13-59. Zaragoza.

Borgna, C.G. (1980): “L'arte rupestre preistorica nell'Europa Occidentale". Tip. Stilgraf. Torino.

Caneva, G. y Salvadori, O. (1988): "Biodeterioration of stone". The Deterioration and Conservation of Stone. Studies and Documents on the Cultural Heritage, 16. UNESCO.

Carrera Ramirez, F. (1987): "Degradación del granito por efecto de los líquenes. Aplicación a la conservación de los petroglifos gallegos". Pátina. Revista de la Escuela de Conservación y Restauración de Bienes Culturales, 2: 19-21. Madrid.

- (1988): "La conservación de los petroglifos de Campo Lameiro". Pátina. Revista de la Escuela de Conservación y Restauración de Bienes Culturales 2: 9-18. Madrid.

- (1993): "La conservación de yacimientos arqueológicos excavados". Arqueología y Conservación. Actas del

(16) Dejamos constancia de nuestro profundo agradecimiento por las valiosas sugerencias recibidas de Victor Barbi Alonso y Luis Xúlio Carballo Arceo. 
Curso de Verano de la Universidad de Vigo (Xinzo, 1992): 101-116. Vigo.

Carrera Ramirez, F. y Barbi Alonso, V. (1992): "Criterios de selección para yacimientos arqueológicos susceptibles de ser conservados". Coloquios Galegos de Museos. Consello Galego de Museos: 19-27. Vigo.

Christensen, P.S. y Rostholm, H. (1986): "Vitlycke gravures rupestres". Vitlycke.

Costas Goberna, F.J. (1984): Petroglifos del litoral Sur de la ría de Vigo (Valles Fragoso y Miñor). Publicaciones del Museo Municipal Quiñones de León (Castrelos), 8. Vigo.

Costas Goberna, F.J. y Fernández Pintos, J. (1987): "Nuevos petroglifos del litoral Sur de la ria de Vigo (Valles Fragoso y Miñor)". Castrelos, 0: 61-89. Vigo.

García Alén, A. y Peña Santos, A. de la (1980): "Grabados rupestres de la provincia de Pontevedra". Fundación P. Barrié de la Maza, Conde de Fenosa. Serie Catalogación Arqueológica y Artística de Galicia. Coruña.

García Bellido, J. (1988): "Problemas urbanísticos de la Ley del Patrimonio Histórico Español: un reto para el urgente desarrollo legislativo autonómico". Ciudad y Territorio, 78, 4: 3-22.

García Blanco, A. y Caballero Zoreda, L. (1992): "La comunicación del parque arqueológico". Jornadas Internacionales de Arqueología de Intervención (S. Sebastián, 1991). Departamento de Cultura del Gobierno Vasco: 373-409. Bilbao.

Helskog, K. (1986): "The rock-carvings in Hjemmeluft/ Jiebmaluokta". Alta.

Peña Santos, A. de la (1978): El arte rupestre gallego al aire libre. Estado actual del problema y modelo para su estudio por comarcas naturales: La Península del Morrazo en Pontevedra. Tesis de Licenciatura inédita. Ejemplares en el Departamento de Historia-1 de la Universidad de Santiago de Compostela.

- (1981): "Nuevos grabados rupestres en Campo Lameiro". Revista de Arqueología, 14: 59. Madrid.

- (1982): "Excavaciones arqueológicas de urgencia en la provincia de Pontevedra durante el año 1981". El Museo de Pontevedra, XXXVI: 67-82. Pontevedra.
- (1984): "Petroglifos". Gran Enciclopedia Gallega, 24: 227-230. Compostela.

- (1984-1985): "Excavación de un complejo de grabados rupestres en Campolameiro (Pontevedra)". Ars Praehistorica, III-IV: 285-290. Madrid.

- (e.p.): "El Grupo Galaico de Arte Rupestre". Actas del Ier. Congrés Internacional de Gravats Rupéstres $i \mathrm{Mu}$ rals (Lleida, 1992). Lleida, Diputación Provincial.

Peña Santos, A. de la y Rey García, J.M. (1993): "El espacio de la representación. El arte rupestre galaico desde una perspectiva territorial". Pontevedra. Revista de Estudios Provinciais, 10: 11-50. Pontevedra.

Peña Santos, A. de la y Vázquez Varela, J.M. (1979): Los petroglifos gallegos. Cuadernos de Sargadelos, 30. Sada (reedición en 1992).

RiBA, D. (1984): “Les gravures rupestres du Val Camonica". Paris.

SiCARI, V. (1990): "Conservación del Arte Rupestre en Australia: Filosofía, política, infraestructura y ordenación". Jornadas sobre Parques con Arte Rupestre (Zaragoza, 1989): 101-110. Zaragoza.

Sobrino BuHigAs, R. (1935): Corpus petroglyphorum Gallaeciae. Seminario d'Estudos Galegos. Compostela.

Sobrino Lorenzo-RuzA, R. (1955): "Datos para el estudio de los petroglifos de tipo atlántico". Actas del III Congreso Nacional de Arqueología (Galicia, 1953): 223 260. Zaragoza.

VÁzquez Varela, J.M. (1990): Petroglifos de Galicia. Biblioteca de Divulgación, Serie "Galicia", 3. Compostela

- (1991): "Ideología y poder en el arte rupestre prehistórico gallego". Cuadernos de Estudios Gallegos XXXIX, 104: 15-22. Compostela.

Velasco Steigrad, F. (1992): "Un modelo de gestión a partir de la declaración de zonas arqueológicas amplias". Jornadas Internacionales de Arqueología de Intervención (S. Sebastián, 1991). Departamento de Cultura del Gobierno Vasco: 75-84. Bilbao.

T. P., 51, n. ${ }^{\circ} 2,1994$ 